\title{
Elemental Analysis and Biological Activities of Chrysophyllum roxburghii G. Don (Sapotaceae) Leaves
}

\section{Prashith Kekuda $\mathrm{TR}^{1}$, Raghavendra $\mathrm{HL}^{2}$, Mallikarjun $\mathrm{N}^{1}$, Swathi $\mathrm{D}^{1}$, Suchitha $\mathrm{Y}^{1}$, Anil Kumar $\mathrm{HS}^{3}$ and Vinayaka $\mathrm{KS}^{4^{*}}$}

\section{${ }^{1}$ Post Graduate Department of Studies and Research in Microbiology, Sahyadri Science} College campus, Kuvempu University, Shivamogga-577203, Karnataka, India
${ }^{2}$ College of Medical and Health Sciences, Wollega University, Post Box No: 395, Nekemte, Ethiopia
${ }^{3}$ Department of Biotechnology Engineering, NMAM Institute of Technology, Nitte-574110, Udupi, Karnataka, India

${ }^{4}$ Department of Botany, Kumadvathi First Grade College, Shimoga Road, Shikaripura, Karnataka, India

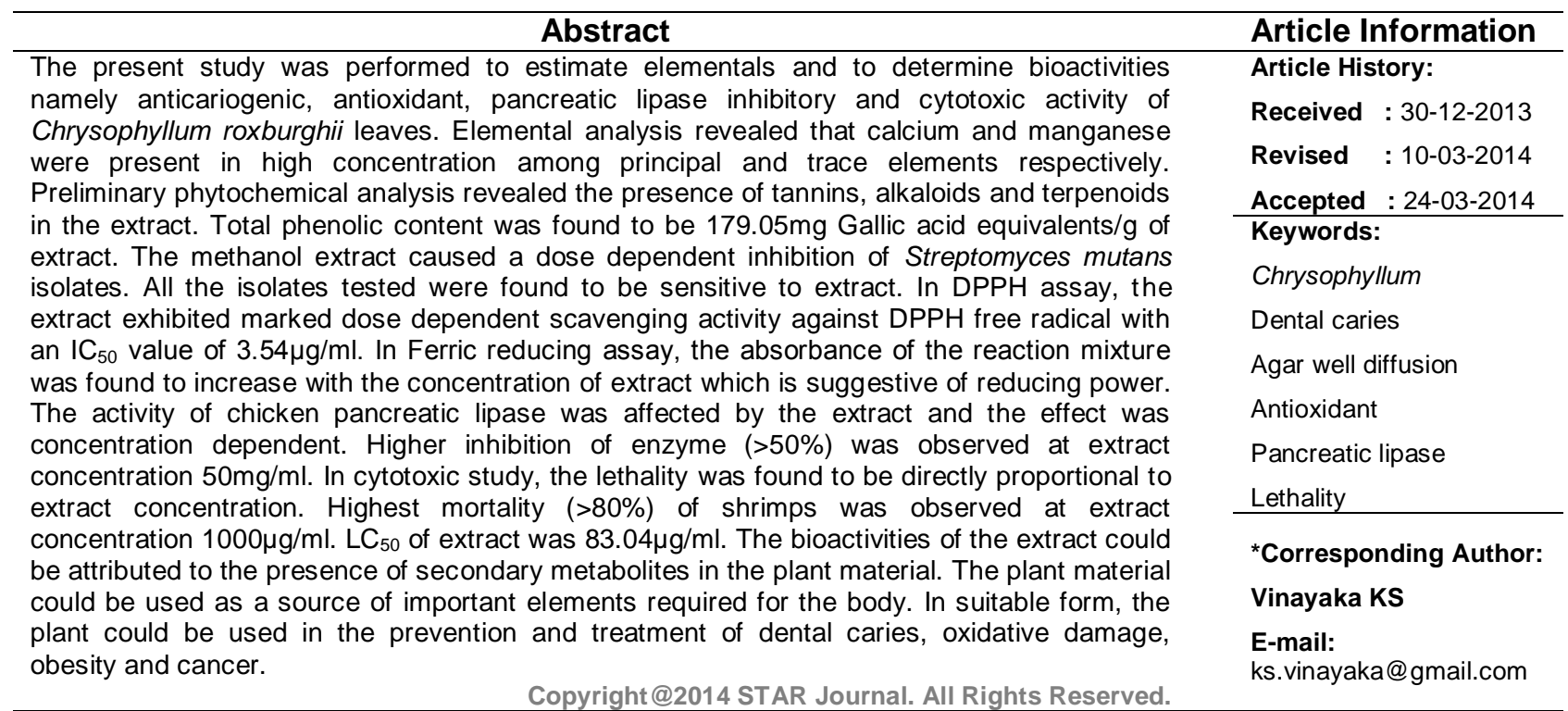

\section{INTRODUCTION}

Chrysophyllum roxburghii G. Don (Syn. C. lanceolatum (BI.) DC.) belongs to the family Sapotaceae. It is commonly called Indian star apple and it is a tree growing up to 15 meters height. It is one of the canopy trees in evergreen forests. It is commonly found in Western Ghats of India and Sri Lanka. The branches are horizontal, leaves are coriaceous, glossy, elliptic, oblong, apex acuminate and nerves numerous. Flowering occurs in April-May and the flowers are greenish white in color and are numerous in axillary fascicles. Seed is a berry (Ramaswamy et al., 2001; Chandrika et al., 2005). The seeds are used in a formulation to treat pneumonia at Sivasagar district of Assam (Acharyya and Sharma, 2004). The ripe fruits are considered edible and tribal people of Anamalais of Western Ghats, India consume these fruits (Ramachandran, 2007). In Mizoram, the plant is locally called Thei pabuan and the ripen fruits are eaten by people of Mizoram (Kar et al., 2013). The fruit is shown to contain an appreciable quantity of minerals and amino acids (Barthakur and Arnold, 1991). In a previous study, Mallikarjun et al. (2011) reported dose dependent antibacterial activity of methanol extract of leaves. Based on literature survey, it has been arrived that the elemental analysis and many of the biological activities of the leaves of $C$. roxburghii are not carried out. Hence, the present study was conducted to determine elemental composition and bioactivities namely anticaries, antioxidant, pancreatic lipase inhibitory and cytotoxic activity of $C$. roxburghii leaves. 


\section{MATERIALS AND METHODS}

\section{Collection and Identification of Plant Material}

The plant material was collected in the month of September 2013 at a place called Haniya, Hosanagara taluk of Shivamogga district, Karnataka, India. A voucher specimen (SSC1549) was deposited in the PG department of Studies and Research in Microbiology, Sahyadri Science College (Autonomous), Shivamogga577203, Karnataka for future reference. The leaves were washed well to remove adhering matter, dried under shade, powdered mechanically and stored in airtight container until use.

\section{Determination of Elemental Composition}

For elemental analysis, a known amount of powdered leaf material $(1.0 \mathrm{gm})$ was digested using mixture of concentrated nitric acid and perchloric acid $(10 \mathrm{ml})$ in a beaker. The powdered material was left in acid mixture for 24 hours and was digested on the hot plate until complete digestion. After digestion, $10 \mathrm{ml}$ of $10 \%$ nitric acid was added to the beaker and the beaker was left for two hours for residue to settle down. The supernatant liquid was filtered though Whatman No. 1. The filtrate was subjected to estimation of elements namely calcium, magnesium, potassium, phosphorus, zinc, iron, copper and manganese using Atomic absorption spectrophotometer (Sarangi et al., 2002).

\section{Preparation of Extract}

The powdered leaf material $(25 \mathrm{~g})$ was extracted in soxhlet apparatus using methanol (HiMedia, Mumbai) as solvent. After extraction, the content was filtered through Whatman filter paper no. 1 and concentrated at $40^{\circ} \mathrm{C}$ under reduced pressure. The weight of the extract was taken. The condensed methanol extract was stored at $4^{\circ} \mathrm{C}$ until use (Kekuda et al., 2012a).

\section{Phytochemical Analysis of Leaf Extract}

The extract obtained after solvent evaporation was subjected to standard tests for detection of phytoconstituents namely alkaloids (Dragendorff's reagent and Mayer's reagent), tannins (ferric chloride test), saponins (frothing test and hemolysis test), glycosides (Salkawski test and Keller-Kiliani test), sterols (Burchard test), flavonoids (Shinoda test) and terpenoids (Salkowski test) (Mallikarjuna et al., 2007; George et al., 2010).

\section{Total Phenolic Content of Leaf Extract}

The content of total phenolics in leaf extract was estimated by Folin-Ciocalteu reagent (FCR) method with some modifications (Rekha et al., 2012). Here, a dilute concentration of leaf extract $(0.5 \mathrm{ml})$ was mixed with 0.5 $\mathrm{ml}$ diluted Folin-Ciocalteu reagent (1:1) and $2 \mathrm{ml}$ of sodium carbonate $(7 \%)$, allowed to stand for 30 minutes and the absorbance was measured colorimetrically at $765 \mathrm{~nm}$. A standard curve was plotted using different concentrations of Gallic acid (standard, 0-1000 $\mu \mathrm{g} / \mathrm{ml}$ ). The concentration of total phenolic compounds was determined as $\mu \mathrm{g}$ Gallic acid equivalents (GAE) from the graph.

\section{Anticaries Activity of Leaf Extract}

The anticaries efficacy of leaf extract was determined by Agar-well-diffusion method (Kekuda et al., 2012a) against 24 oral isolates of Streptococcus mutans (S-1 to S-24) recovered from teeth samples of dental caries patients. The test bacteria were inoculated into sterile Brain heart infusion broth (HiMedia, Mumbai) tubes and
Sci. Technol. Arts Res. J., Jan-March 2014, 3(1): 14-20

incubated at $37^{\circ} \mathrm{C}$ for 24 hours. The broth cultures were swabbed uniformly on solidified sterile Brain heart infusion agar (HiMedia, Mumbai) plates using sterile cotton swab. Then, wells of $6 \mathrm{~mm}$ diameter were punched in the inoculated plates with the help of sterile cork borer and the leaf extract (10 and $20 \mathrm{mg} / \mathrm{ml}$ of $10 \%$ dimethyl sulfoxide [DMSO; HiMedia, Mumbai]), Standard antibiotic (Chloramphenicol, $1 \mathrm{mg} / \mathrm{ml}$ ) and Control (10\% DMSO) were added into respectively labeled wells. The inoculated plates were incubated at $37^{\circ} \mathrm{C}$ for 24 hours in upright position and the zone of inhibition formed around the well was measured with a ruler. The experiment was carried in triplicates to get average reading.

\section{Antioxidant Activity of Leaf Extract DPPH Free Radical Scavenging Activity}

The radical scavenging ability of leaf extract and ascorbic acid (reference standard) was tested on the basis of the radical scavenging effect on the DPPH (1,1Diphenyl-2-picryl-hydrazyl) free radical (Rekha et al., 2012). Here, $2 \mathrm{ml}$ of different concentrations of leaf extract and ascorbic acid ( 1 to $200 \mu \mathrm{g} / \mathrm{ml}$ ) were mixed with $2 \mathrm{ml}$ of DPPH solution $(0.002 \%$ in methanol) in clean and labeled tubes. The tubes were incubated at room temperature in dark for 30 minutes and the absorbance was measured at $517 \mathrm{~nm}$ using UV-Visible Spectrophotometer (Elco, SL159). The absorbance of the DPPH control (2ml $\mathrm{DPPH}+2 \mathrm{ml}$ methanol) was also noted. The scavenging activity of the extract was calculated using the formula:

$$
\text { Scavenging activity }(\%)=(A-B) / A \times 100 \text {, }
$$

where $A$ is absorbance of DPPH control and $B$ is absorbance of DPPH and extract/standard combination. The $\mathrm{IC}_{50}$ value for the extract was calculated by Origin 6.0 software. $I_{50}$ denotes the concentration of extract required to scavenge $50 \%$ of DPPH free radicals.

\section{Ferric Reducing Activity}

The reducing ability of leaf extract was tested by ferric reducing assay. Briefly, different concentrations (1 to $200 \mu \mathrm{g} / \mathrm{ml}$ ) of extract and ascorbic acid (reference standard) in $1 \mathrm{ml}$ of methanol were mixed in separate tubes with $2.5 \mathrm{ml}$ of phosphate buffer $(200 \mathrm{mM}, \mathrm{pH} 6.6)$ and $2.5 \mathrm{ml}$ of potassium ferricyanide (1\%). The tubes were placed in water bath for 20 minutes at $50^{\circ} \mathrm{C}$, cooled rapidly and added with $2.5 \mathrm{ml}$ of trichloroacetic acid $(10 \%)$ and $0.5 \mathrm{ml}$ of ferric chloride $(0.1 \%)$. The amount of iron (II)ferricyanide complex formed was determined by measuring the formation of Perl's Prussian blue at 700nm after 10minutes. The increase in absorbance of the reaction mixtures indicates increased reducing power (Rekha et al., 2012).

\section{Pancreatic Lipase Activity of Leaf Extract}

The inhibitory effect of leaf extract and Orlisat (reference standard) against lipase was tested against lipase extracted from the pancreas of chicken. Lipase inhibitory activity of different concentrations of leaf extract and Orlisat was tested by mixing $100 \mu \mathrm{l}$ of each concentration of leaf extract, $8 \mathrm{ml}$ of oil emulsion and $1 \mathrm{ml}$ of chicken pancreatic lipase followed by an incubation of 60 minutes. The reaction was stopped by adding $1.5 \mathrm{ml}$ of a mixture solution containing acetone and $95 \%$ ethanol (1:1). The liberated fatty acids were determined by titrating the solution against $\mathrm{NaOH}(0.02 \mathrm{M})$ using phenolphthalein as an indicator (Kumar et al., 2011). The inhibition of lipase activity (\%) was calculated using the formula: 
Prashith Kekuda et al.,

Lipase inhibition $(\%)=(A-B) / A \times 100$,

where $A$ is lipase activity, $B$ is activity of lipase when incubated with leaf extract.

\section{Cytotoxic Activity of Methanol Extract}

Brine Shrimp Lethality bioassay was performed in order to determine cytotoxic nature of the leaf extract. The eggs of brine shrimp Artemia salina (Nihon Animal Pharmaceutical Inc., Tokyo, Japan) were hatched in a container filled with air-bubbled artificial sea water which was prepared with $10 \mathrm{~g}$ of a commercial salt mixture (GEX Inc., Osaka, Japan) and $500 \mathrm{ml}$ of distilled water. After 3648 hours, the phototropic shrimps were collected. 25 shrimps were transferred into each vial containing $5 \mathrm{ml}$ of artificial sea water with different concentrations of leaf extract $(10,100$ and $1000 \mu \mathrm{g} / \mathrm{ml})$. The vials were incubated at $25^{\circ} \mathrm{C}$ and surviving shrimps were counted microscopically after 24 hours. Potassium dichromate was used as positive control (Kekuda et al., 2012a). LC L $_{50}$ value was calculated and the value $>1000 \mu \mathrm{g} / \mathrm{ml}$ was considered non-toxic.

\section{Statistical Analysis}

The experiments were performed in triplicates. The results are represented as Mean \pm Standard deviation. The $I C_{50}$ values were calculated by Origin 6.0 software.

\section{RESULTS}

An appreciable quantity of elements was detected in the leaf material. Among the major elements, Calcium was detected in high quantity followed by potassium, magnesium and phosphorus. In case of minor elements, manganese was detected in high concentration followed by iron, copper and zinc (Table 1).

Table 1: Elemental composition of leaf material.

\begin{tabular}{lc}
\hline \multicolumn{1}{c}{ Element } & Quantity $(\mathbf{p p m})$ \\
\hline Calcium & $10125.10 \pm 10.33$ \\
Potassium & $7000.05 \pm 11.10$ \\
Magnesium & $4125.65 \pm 08.45$ \\
Phosphorus & $900.45 \pm 10.00$ \\
Manganese & $640.47 \pm 06.56$ \\
Iron & $330.20 \pm 05.12$ \\
Copper & $17.25 \pm 02.15$ \\
Zinc & $16.49 \pm 01.14$ \\
\hline
\end{tabular}

The extract yield was $4.16 \%$. Preliminary phytochemical screening of leaf extract revealed the presence of phytoconstituents namely of tannins, alkaloids and terpenoids. The total phenolic content of leaf extract was found to be $179.05 \pm 0.5 \mathrm{mg} \mathrm{GAE} /$ gram of extract.

The result of anticaries activity of leaf extract against oral isolates of $S$. mutans is shown in Table 2 and Figure 1. Results were recorded as presence or absence of zones of inhibition around the well. The inhibitory zone around the well indicated the absence of bacterial growth and reported as positive and the absence of zone as negative. It was found that the leaf extract caused inhibition of $S$. mutans isolates in a dose dependent manner i.e., the diameter of inhibition zone increased with the increase of extract concentration. The zone of inhibition ranged from 1.2 to $2.3 \mathrm{~cm}$ and 0.8 to $1.9 \mathrm{~cm}$ at extract concentration of $20 \mathrm{mg} / \mathrm{ml}$ and $10 \mathrm{mg} / \mathrm{ml}$ respectively. Inhibition caused by standard antibiotic was
Sci. Technol. Arts Res. J., Jan-March 2014, 3(1): 14-20

higher than that of leaf extract. DMSO did not cause any inhibition of bacterial isolates.

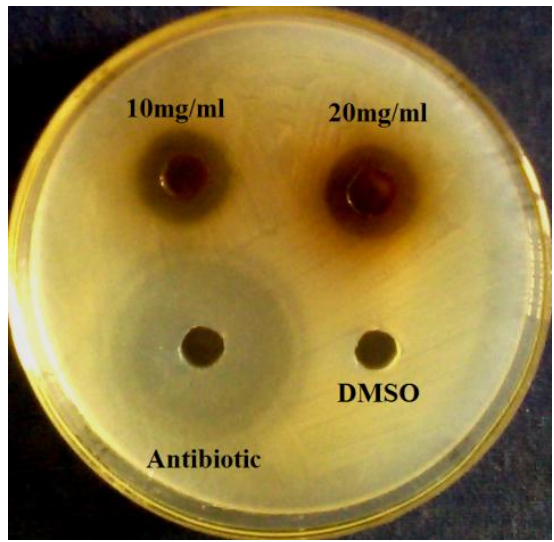

Figure 1: Inhibitory effect of leaf extract against isolate S-11.

Table 2: Anticaries activity of leaf extract against $S$. mutans isolates.

\begin{tabular}{lllll}
\hline & \multicolumn{3}{c}{ Zone of inhibition in cm } \\
\cline { 2 - 4 } Isolates & Methanol extract & Standard & DMSO \\
\cline { 2 - 4 } & $\mathbf{2 0 \mathrm { mg } / \mathbf { m l }}$ & $\mathbf{1 0 m g} / \mathbf{m l}$ & & \\
\hline S-1 & $1.7 \pm 0.1$ & $1.5 \pm 0.0$ & $2.4 \pm 0.2$ & $00 \pm 0.0$ \\
S-2 & $1.6 \pm 0.0$ & $1.4 \pm 0.1$ & $2.6 \pm 0.2$ & $00 \pm 0.0$ \\
S-3 & $1.4 \pm 0.0$ & $1.2 \pm 0.0$ & $2.3 \pm 0.1$ & $00 \pm 0.0$ \\
S-4 & $1.5 \pm 0.1$ & $1.3 \pm 0.0$ & $2.2 \pm 0.0$ & $00 \pm 0.0$ \\
S-5 & $1.8 \pm 0.2$ & $1.6 \pm 0.0$ & $2.6 \pm 0.0$ & $00 \pm 0.0$ \\
S-6 & $1.5 \pm 0.0$ & $1.1 \pm 0.0$ & $2.8 \pm 0.2$ & $00 \pm 0.0$ \\
S-7 & $1.9 \pm 0.1$ & $1.6 \pm 0.1$ & $2.4 \pm 0.1$ & $00 \pm 0.0$ \\
S-8 & $1.8 \pm 0.0$ & $1.5 \pm 0.1$ & $2.1 \pm 0.0$ & $00 \pm 0.0$ \\
S-9 & $1.5 \pm 0.0$ & $1.2 \pm 0.0$ & $2.3 \pm 0.1$ & $00 \pm 0.0$ \\
S-10 & $1.9 \pm 0.2$ & $1.6 \pm 0.1$ & $2.9 \pm 0.2$ & $00 \pm 0.0$ \\
S-11 & $1.2 \pm 0.0$ & $1.1 \pm 0.0$ & $2.6 \pm 0.0$ & $00 \pm 0.0$ \\
S-12 & $1.2 \pm 0.0$ & $0.8 \pm 0.0$ & $2.3 \pm 0.0$ & $00 \pm 0.0$ \\
S-13 & $1.6 \pm 0.1$ & $1.4 \pm 0.0$ & $2.4 \pm 0.0$ & $00 \pm 0.0$ \\
S-14 & $1.6 \pm 0.1$ & $1.3 \pm 0.0$ & $2.4 \pm 0.1$ & $00 \pm 0.0$ \\
S-15 & $1.8 \pm 0.1$ & $1.5 \pm 0.0$ & $2.7 \pm 0.2$ & $00 \pm 0.0$ \\
S-16 & $2.1 \pm 0.2$ & $1.8 \pm 0.1$ & $2.3 \pm 0.0$ & $00 \pm 0.0$ \\
S-17 & $1.8 \pm 0.1$ & $1.6 \pm 0.0$ & $2.1 \pm 0.0$ & $00 \pm 0.0$ \\
S-18 & $2.0 \pm 0.2$ & $1.7 \pm 0.1$ & $2.6 \pm 0.2$ & $00 \pm 0.0$ \\
S-19 & $1.5 \pm 0.0$ & $1.2 \pm 0.0$ & $2.7 \pm 0.2$ & $00 \pm 0.0$ \\
S-20 & $2.3 \pm 0.2$ & $1.9 \pm 0.2$ & $2.3 \pm 0.0$ & $00 \pm 0.0$ \\
S-21 & $1.6 \pm 0.0$ & $1.2 \pm 0.0$ & $2.1 \pm 0.0$ & $00 \pm 0.0$ \\
S-22 & $1.4 \pm 0.0$ & $1.2 \pm 0.0$ & $2.6 \pm 0.2$ & $00 \pm 0.0$ \\
S-23 & $1.8 \pm 0.1$ & $1.5 \pm 0.1$ & $2.5 \pm 0.2$ & $00 \pm 0.0$ \\
S-24 & $1.9 \pm 0.2$ & $1.6 \pm 0.0$ & $2.9 \pm 0.2$ & $00 \pm 0.0$ \\
\hline & & & &
\end{tabular}

Figure 2 shows the radical scavenging activity of different concentrations of leaf extract and ascorbic acid. Both extract and ascorbic acid exhibited marked scavenging activity and the activity was dose dependent. The scavenging activity of ascorbic acid $\left(\mathrm{IC}_{50} 2.29 \mu \mathrm{g} / \mathrm{ml}\right)$ was greater than that of leaf extract $\left(\mathrm{IC}_{50} 3.54 \mu \mathrm{g} / \mathrm{ml}\right)$.

The reduction of $\mathrm{Fe}^{3+}$ to $\mathrm{Fe}^{2+}$ was investigated in the presence of extract to examine the reducing power of extract and the result is shown in Figure 3 . The absorbance of the reaction mixture was found to increase with the increase in concentration of extract and reference standard which is suggestive of reducing power. 
Prashith Kekuda et al.,

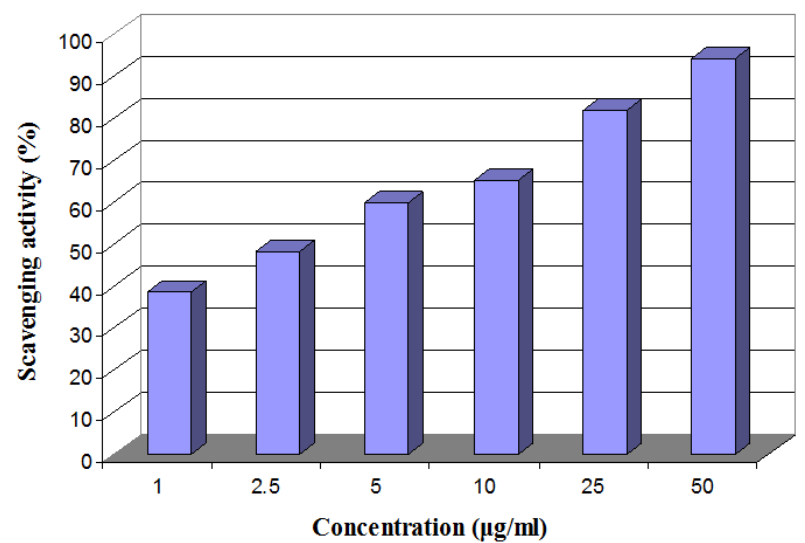

Figure 2: DPPH free radical scavenging activity of leaf extract.

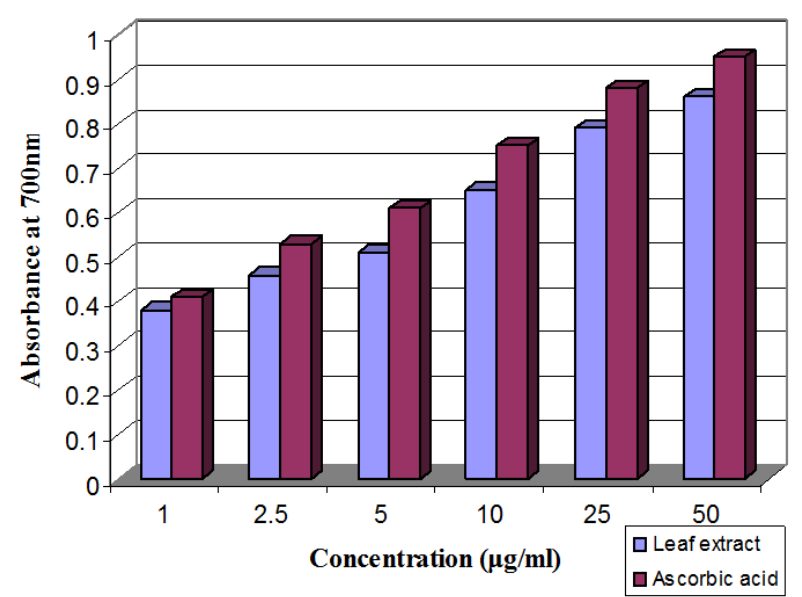

Figure 3: Ferric reducing activity of leaf extract.

Inhibitory activity on chicken pancreatic lipase of different concentrations of leaf extract was determined using olive oil as the substrate. It was observed that the activity of lipase was affected when incubated with the methanol extract. The inhibitory activity was found to be dose dependent i.e., higher inhibition of enzyme was observed on increasing the concentration of extract. An inhibition of greater than $50 \%$ was observed at extract concentration $50 \mathrm{mg} / \mathrm{ml}$ (Figure 4). Orlisat showed high inhibitory activity $\left(\mathrm{IC}_{50} 6.03 \mu \mathrm{g} / \mathrm{ml}\right)$ against lipase when compared to leaf extract.

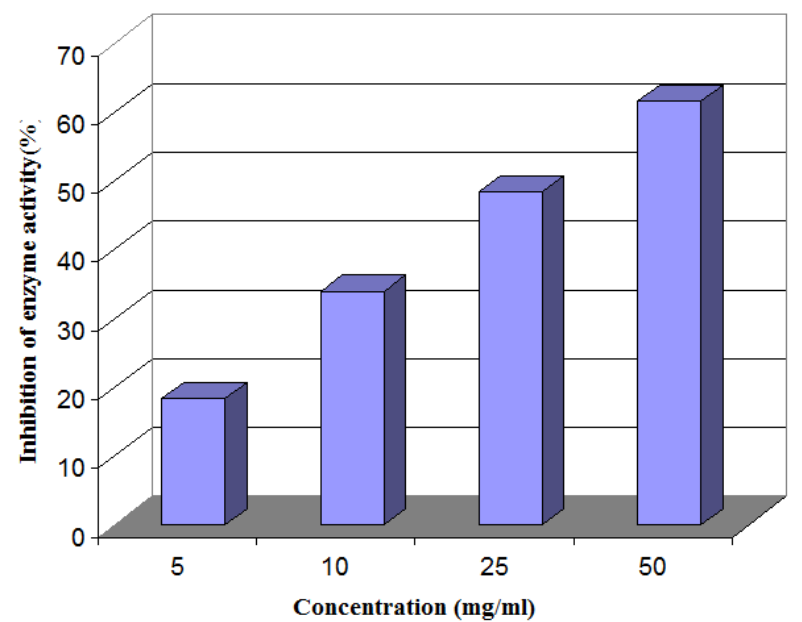

Figure 4: Pancreatic lipase inhibitory activity of methanol extract.
Sci. Technol. Arts Res. J., Jan-March 2014, 3(1): 14-20

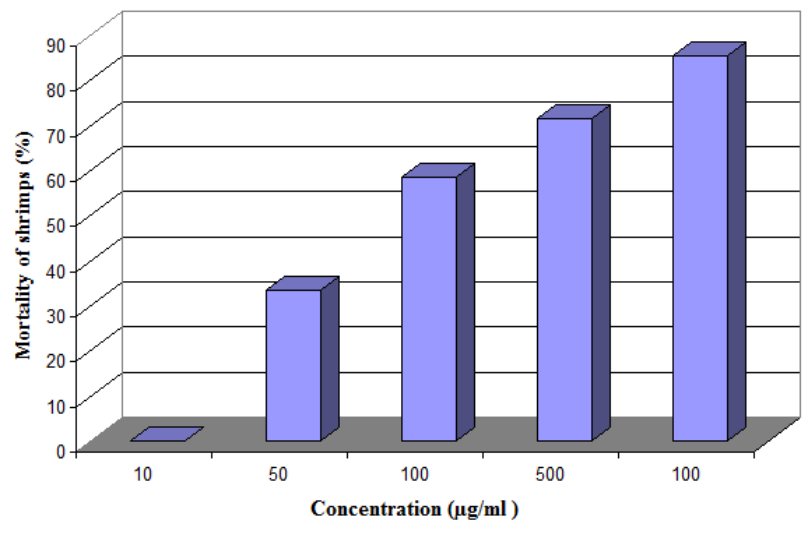

Figure 5: Cytotoxic activity of leaf extract.

The cytotoxic activity of different concentrations of methanol extract in terms of mortality of brine shrimps is presented in Figure 5. The degree of lethality was found to be directly proportional to the concentration of the extract. Highest mortality $(>80 \%)$ was observed at extract concentration $1000 \mu \mathrm{g} / \mathrm{ml}$ where as no mortality was observed at $10 \mu \mathrm{g} / \mathrm{ml}$. LC 50 of extract was found to be $83.04 \mu \mathrm{g} / \mathrm{ml}$ and thus the extract is toxic. Potassium dichromate $\left(\mathrm{LC}_{50} 32.04 \mu \mathrm{g} / \mathrm{ml}\right)$ showed marked cytotoxic effect when compared to leaf extract.

\section{DISCUSSION}

All individuals required carbohydrates, proteins, fats, vitamins and minerals in their nutrition. Nutrients such as carbohydrates, proteins and fats are consumed in larger quantity and are called macronutrients. However, vitamins and minerals are consumed in lesser quantity and are referred to as micronutrients. The mineral elements are inorganic substances present all body tissues and fluids in the body and their presence is essential to life. Elements are broadly classified into principal elements or major elements and trace elements or minor elements based on the quantity being consumed. Minerals such as calcium, potassium, magnesium and phosphorus forms the principal elements while iron, copper, manganese and zinc forms the trace elements. Although minerals yield no energy, they are important for calcification of bone, blood coagulation, neuromuscular activity, acid base equilibrium, enzyme activity, osmotic regulation etc. (Soetan et al., 2010; Vinayaka et al., 2013). In the present study, an appreciable quantity of major and minor elements was detected in the leaf of $C$. roxburghii. Among the principal elements, calcium was present in high concentration followed by potassium, magnesium and phosphorus. Among trace elements, manganese was detected in high concentration followed by iron, copper and zinc. In a previous study, Barthakur and Arnold (1991) evaluated chemical composition of fruit of $C$. roxburghii. Of the 14 macro and micronutrients studied, potassium was the most highly concentrated. The fruit also contained considerably higher concentrations of calcium, iron, manganese, phosphorus and others.

Among the oral diseases, dental caries is one of the most prevalent infectious diseases affecting people of all age groups all over the world. It is chronic and is caused by an interaction between microflora of oral cavity, diet, dentition and oral environment. It affects $60-90 \%$ of young population. A large number of microorganisms viz., mutans streptococci, lactobacilli and Actinomyces are 
Prashith Kekuda et al.,

known to be involved in causing dental caries. Among cariogenic flora, Streptococcus mutans is considered as the principal aetiological agent, however, additional acidogenic microorganisms such as lactobacilli may also be involved. The cariogenicity of $S$. mutans is ascribed to its ability to metabolize dietary carbohydrates, to produce acid and tolerate acid, to adhere to and to form biofilm on tooth surfaces (Ferrazzano et al., 2009; Almeida et al., 2012; Brighenti et al., 2012; Narotzki et al., 2012). Antimicrobial mouth-rinses and antibiotics are most commonly used to prevent and treat dental caries. However, these chemicals have shown to have some drawbacks such as development of resistance among cariogenic flora, high cost and possible side effects (Guimaraes et al., 2006; Dzidic et al., 2008). Hence, several investigators have screened the efficacy of natural products, in particular plants, against microorganisms implicated in causing dental caries. In our study, the leaf extract showed a dose dependent inhibitory activity against oral isolates of $S$. mutans. It has been experimentally shown that plants and their products exhibit marked inhibitory activity against cariogenic flora (Fani and Kohanteb, 2007; Jose and Beegum, 2007; Ferrazzano et al., 2009; Almeida et al., 2012; Vivek et al., 2013).

It is well known that reactive oxygen species (ROS) such as superoxide radical, hydroxyl radical, singlet oxygen, peroxyl radical, hydrogen peroxide are produced during oxidative stress. These radicals are known to be involved in several pathological conditions such as aging, cancer, neurodegenerative disease, coronary heart diseases etc. Antioxidant defenses in organisms against ROS may be of endogenous (enzymatic and monenzymatic) or dietary origin (vitamins, carotenoids, flavonoids, etc.). An antioxidant is defined as any substance when present at low concentrations compared with those of an oxidizable substrate, significantly delays or prevents oxidation of that substrate. Synthetic antioxidants such as BHA, BHT, PG and others are known to possess some possible toxic or carcinogenic effects. Hence, search for antioxidants from natural origin, in particular from plants, has been greatly increased (Jayaprakasha et al., 2001; Chang et al., 2007; Kim et al., 2006; Stoilova et al., 2007; Mohamed et al., 2013). Polyphenolic compounds including flavonoids are found in various parts of both edible and inedible plants. They are reported to exhibit multiple biological effects, including antioxidant activity. Phytochemicals such as flavonoids, tannins, anthocyanins and other phenolic constituents present in food of plant origin are potential antioxidants. Phenolic compounds present in dietary supplements can protect the body against oxidative damage (Yuan et al., 2005; Wojdylo et al., 2007; Kim et al., 2006; Stoilova et al., 2007).

DPPH radical scavenging assay is one of the important antioxidant assays which is simple, easy to perform and can be done in relatively shorter period of time. DPPH, the relatively stable, organic, nitrogen centered free radical having absorption maxima at 515$520 \mathrm{~nm}$ in alcoholic solution. It is widely used in the determination of antioxidant activity, in terms of radical scavenging activity, of single compounds as well as of different plant extracts (Hinneburg et al., 2006; Katalinic et al., 2006; Wojdylo et al., 2007; Kim et al., 2006; Rekha et al., 2012; Junaid et al., 2013; Kekuda et al., 2013). The scavenging effect of antioxidants is due to their hydrogen
Sci. Technol. Arts Res. J., Jan-March 2014, 3(1): 14-20

donating ability. The antioxidants reduce the purple colored DPPH radical to a yellow colored compound diphenylpicrylhydrazine, and the extent of reaction will depend on the hydrogen donating ability of the antioxidants (Bondent et al., 1997). In the present study, leaf extract exhibited a marked scavenging potential. However, scavenging potential of leaf extract was lesser when compared to ascorbic acid. Although the scavenging abilities of leaf extract was lesser than that of ascorbic acid, it was evident that the extracts showed hydrogen donating ability and therefore the extracts could serve as free radical scavengers, acting possibly as primary antioxidants (Chung et al., 2006).

We investigated the $\mathrm{Fe}^{+3} / \mathrm{Fe}^{+2}$ transformations in the presence of different concentrations of leaf extract in order to measure the reducing power. Here, the presence of reductants (antioxidants) in the extract would reduce $\mathrm{Fe}^{+3}$ to $\mathrm{Fe}^{+2}$ by donating an electron. The amount of $\mathrm{Fe}^{+2}$ complexe formed after incubation can be determined by measuring the formation of Perl's Prussian blue at 700nm. Increasing absorbance at $700 \mathrm{~nm}$ indicates an increase in reductive ability. The reducing capacity of an extract or a compound usually serves as a significant indicator of its potential antioxidant activity (Chung et al., 2006; Hsu et al., 2006). Ferric reducing assay is routinely performed to investigate reducing potential of various kinds of samples (Jayaprakasha et al., 2001; Hinneburg et al., 2006; Kim et al., 2007; Rekha et al., 2012; Junaid et al., 2013). In the present study, it was found that the reducing power of leaf extract increased with the increase of its concentration. It is evident that the leaf extract possess reductive potential and could serve as electron donors, terminating the radical chain reactions (Chung et al., 2006).

One of the most important choices of treatment of obesity is the development of inhibitors of nutrient digestion and absorption. Inhibition of pancreatic lipase is the most widely studied mechanism to determine the efficacy of natural products as antiobesity agents. Pancreatic lipase is the main lipid-digesting enzyme that removes fatty acids from $\alpha$ and $\alpha$ ' position of dietary triglycerides yielding the lipolytic product $\beta$-monoglyceride and long-chain saturated and polyunsaturated fatty acids. Orlistat, one of the two clinically approved drugs for treatment of obesity, act by inhibiting pancreatic lipase. Even though it is one of the best-selling drugs worldwide, it has side effects such as oily stools, oily spotting, and flatulence (Shi and Burn, 2004; Birari and Bhutani, 2007; Yun, 2010; Kumar et al., 2011 Phcog J). This prompted research for the identification of inhibitors that lack the side effects. Phytochemicals of plants present an exciting opportunity for discovering newer anti-obesity agents. Several plants, for example Taraxacum officinale, Nomame herba, Vitis vinifera etc, have to shown to be promising sources of anti-obesity agents (Zhang et al., 2008; Moreno et al., 2003; Yamamoto et al., 2000). In the present study, the leaf extract was found to inhibit the activity of chicken pancreatic lipase in a dose dependent manner. Inhibition of chicken pancreatic lipase has been studied by researchers in order to screen anti-obesity activity of a variety of samples. In a study, ethyl acetate extract of Terminalia bellerica seeds has shown concentration dependent inhibition of chicken pancreatic lipase (Kumar et al., 2010). The methanol extract of a macrolichen Everniastrum cirrhatum was found to inhibit activity of chicken pancreatic lipase in a concentration dependent manner (Kumar et al., 2011 phcog j). In 
Prashith Kekuda et al.,

another study, Kekuda et al. (2011) observed dose dependent inhibition of chicken pancreatic lipase by extract of Streptomyces species from Western Ghats of Karnataka.

Brine shrimp lethality bioassay is a rapid method that utilizes only 24 hours and is inexpensive. This assay is based on the ability of the extract to exhibit lethality in laboratory cultured brine shrimp. The assay utilizes a large number of organisms for validation and a relatively small amount of sample. It does not need animal serum as needed for other methods of cytotoxicity testing. This test is considered to be very useful in determining biological activities such as cytotoxic, phototoxic, pesticidal, trypanocidal, enzyme inhibition, and ion regulation activities. It can also be extrapolated for cellline toxicity and antitumor activity (Luis et al., 2002; Hossain et al., 2009; Raghavendra et al., 2010; Kekuda et al., 2010). In the present study, we evaluated cytotoxic nature of leaf extract by brine shrimp lethality assay. The extract demonstrated dose dependent cytotoxic effect with $\mathrm{LC}_{50}$ of $83.04 \mu \mathrm{g} / \mathrm{ml}$. Studies have shown that plant extracts exhibit lethal effect on brine shrimp. Raghavendra et al. (2010) showed cytotoxic effect of methanol extract of Putranjiva roxburghii seeds with $\mathrm{LC}_{50}$ of $427.74 \mu \mathrm{g} / \mathrm{ml}$. The leaf extract of Abrus pulchellus was found to cause dose dependent lethal effect with $\mathrm{LC}_{50}$ of $281.70 \mu \mathrm{g} / \mathrm{ml}$ (Kekuda et al., 2010). Leaf extract of Croton gibsonianus was found to exhibit cytotoxicity with LC $_{50}$ of $109.48 \mu \mathrm{g} / \mathrm{ml}$ (Kekuda et al., 2012b).

\section{CONCLUSION}

The study reveals the presence of an appreciable quantity of various minerals in the leaf material of $C$. roxburghii. The plant can be a potential source of minerals that are required for normal physiology of the individual. The leaf extract also displayed anticaries, pancreatic lipase inhibitory, antioxidant and cytotoxic properties. The observed bioactivities could be ascribed to the presence of secondary metabolites. Further studies are under progress to separate active principles from the leaf extract and to determine their bioactivities.

\section{ACKNOWLEDGEMENTS}

The authors express sincere thanks to Principal, Sahyadri Science College (Autonomous) for providing all facilities and moral support to conduct work. Authors also thank Mr. Venugopal TM for help provided.

\section{REFERENCES}

Acharyya, B.K., Sharma, H.K. (2004). Folklore medicinal plants of Mahmora area, Sivasagar district, Assam. Indian Journal of Traditional Knowledge 3(4): 365-372.

Almeida, A.A.P., Naghetini, C.C., Santos, V.R., Antonio, A.G., Farah, A., Gloria, M.B.A. (2012). Influence of natural coffee compounds, coffee extracts and increased levels of caffeine on the inhibition of Streptococcus mutans. Food Research International 49: 459-461.

Barthakur, N.N., Arnold, N.P. (1991). A chemical analysis of the Indian star apple (Chrysophyllum roxburghii) fruit. Journal of Food Composition and Analysis 4(4): 354-359.

Birari, R.B., Bhutani, K.K. (2007). Pancreatic lipase inhibitors from natural sources: unexplored potential. Drug Discovery Today 12: 879-889.

Bondent, V., Brand-Williams, W., Bereset, C. (1997). Kinetic and mechanism of antioxidant activity using the DPPH
Sci. Technol. Arts Res. J., Jan-March 2014, 3(1): 14-20

free radical methods. Lebensmittel Wissenschaft Technologie 30: 609-615.

Brighenti, F.L., Gaetti-Jardim, E., Danelon, M., Evangelista, G.V., Delbem, A.C.B. (2012). Effect of Psidium cattleianum leaf extract on enamel demineralisation and dental biofilm composition in situ. Archives of Oral Biology 57: 1034-1040.

Chandrika, U.G., Jansz, E.R., Warnasuriya, N.D. (2005). Identification and HPLC quantification of carotenoids of the fruit pulp of Chrysophyllum roxburghii. Journal of National Foundation Sri Lanka 33(2): 93-98.

Chang, H., Ho, Y., Sheu, M., Lin, Y., Tseng, M., Wu, S., Huang, G., Chang, Y. (2007). Antioxidant and free radical scavenging activities of Phellinus merrillii extracts. Botanical Studies 48: 407-417.

Chung, Y., Chien, C., Teng, K., Chou, S. (2006). Antioxidative and mutagenic properties of Zanthoxylum ailanthoides Sieb and zucc. Food Chemistry 97: 418-425.

Dzidic, S., Suskovic, J., Kos, B. (2008). Antibiotic Resistance Mechanisms in Bacteria: Biochemical and Genetic Aspects. Food Technology and Biotechnology 46(1): 1121

Fani, M.M., Kohanteb, J., Dayaghi, M. (2007). Inhibitory activity of garlic (Allium sativum) extract on multidrugresistant Streptococcus mutans. Journal of Indian Society of Pedodontics and Preventive Dentistry 25(4): 164-168.

Ferrazzano, G.F., Amato, I., Ingenito, A., De Natale, A., Pollio, A. (2009). Anticariogenic effects of polyphenols from plant stimulant beverages (cocoa, coffee, tea). Fitoterapia 80: 255-262.

George, N.J., Obot, J.B., Ikot, A.N., Akpan, A.E., Obi-Egbedi, N.O. (2010). Phytochemical and antimicrobial properties of leaves of Alchonea cordifolia. E-Journal of Chemistry 7(3): 1071-1079.

Guimaraes, A.R.D., Peres, M.A., Vieira, R.S., Ferreira, R.M., Ramos-Jorge, M.L., Apolinario, S., Debom, A. (2006). Self-perception of side effects by adolescents in a chlorhexidine-fluoridebased preventive oral health program. Journal of Applied Oral Science 14(4): 291-296.

Hinneburg, I., Dorman, D.H.J., Hiltunen, R. (2006). Antioxidant activities of extracts from selected culinary herbs and spices. Food Chemistry 97: 122-129.

Hossain, A.M., Ferdous, T., Salehuddin, S.M., Das, A.K. (2009). In vitro cytotoxicity (LC50) of extracts obtained from the seeds of Zea mays. Asian Journal of Food and Agro-Industry 2(3): 336-34.

Hsu, B., Coupar, I.M., Ng, K. (2006). Antioxidant activity of hot water extract from the fruit of the Doum palm, Hyphaene thebaica. Food Chemistry 98: 317-328.

Jayaprakasha, G.K., Singh, R.P., Sakariah, K.K. (2001). Antioxidant activity of grape seed (Vitis vinifera) extracts on peroxidation models in vitro. Food Chemistry 73: 285290.

Jose, S., Beegum, G.R.J. (2007). In vitro susceptibility of viridans streptococci to leaf extracts of Mangifera indica. Indian Journal of Microbiology 47: 160-163.

Junaid, S., Rakesh, K.N., Dileep, N., Poornima, G., Kekuda, P.T.R., Mukunda, S. (2013). Total phenolic content and antioxidant activity of seed extract of Lagerstroemia speciosa L. Chemical Science Transactions 2(1): 75-80.

Kar, A., Bora, D., Borthakur, S.K., Goswami, N.K., Saharia, D. (2013). Wild edible plant resources used by the Mizos 


\section{Prashith Kekuda et alo,}

of Mizoram, India. Kathmandu University Journal of Science, Engineering and Technology 9(1): 106-126.

Katalinic, V., Milos, M., Kulisic, T., Jukic, M. (2006). Screening of 70 medicinal plant extracts for antioxidant capacity and total phenols. Food Chemistry 94: 550-557.

Kekuda, P.T.R., Manasa, M., Poornima, G., Abhipsa, V., Rekha, C., Upashe, S.P., Raghavendra, H.L. (2013). Antibacterial, cytotoxic and antioxidant potential of Vitex negundo var. negundo and Vitex negundo var. purpurascens- A comparative study. Science Technology and Arts Research Journal 2(3): 59-68.

Kekuda, P.T.R., Raghavendra, H.L., Surabhi, K.S., Preethi, H.R., Swarnalatha, S.P. (2010). Cytotoxic activity of methanol extract of Abrus pulchellus Wall (Fabaceae) leaves. Biomedicine 30(3): 377-379.

Kekuda, P.T.R., Raghavendra, H.L., Swathi, D., Venugopal, T.M., Vinayaka, K.S. (2012a). Antifungal and cytotoxic activity of Everniastrum cirrhatum (Fr.) Hale. Chiang Mai Journal of Science 39(1); 2012: 76-83.

Kekuda, P.T.R., Shobha, K.S., Onkarappa, R. (2011). Pancreatic lipase Inhibitory and cytotoxic potential of a Streptomyces species isolated from Western Ghat soil, Agumbe, Karnataka, India. International Journal of Pharmaceutical and Biological Archives 2(3): 932-937.

Kekuda, P.T.R., Raghavendra, H.L., Vinayaka, K.S. (2012b). Cytotoxic activity of Croton gibsonianus Nimm. Grah. Science, Technology and Arts Research Journal 1(1): 5759.

Kim, S., Jeong, S., Park, W., Nam, K.C., Ahn, D.U., Lee, S. (2006). Effect of heating conditions of grape seeds on the antioxidant activity of grape seed extracts. Food Chemistry 97: 472-479.

Kumar, A.H.S., Bopanna, M.M., Gowda, S.T., Jenifer, R.R., Somanna, S.H. (2010). Anti-lipase activity of ethyl acetate extract of Terminalia bellerica Roxb. seeds. Research and Reviews in Biomedicine and Biotechnology 1(1): 60-63.

Kumar, A.H.S., Kekuda, P.T.R., Vinayaka, K.S., Swathi, D., Venugopal, T.M. (2011). Anti-obesity (Pancreatic lipase inhibitory) activity of Everniastrum cirrhatum (Fr.) Hale (Parmeliaceae). Pharmacognosy Journal 3(19): 65-68.

Luis, C.J., Zairo, L.H., Pillar, P., Naira, D.G. (2002). A comparison between two brine shrimp assay to detect in vitro cytotoxicity in marine natural products. BMC Biotechnology 2(17): 1-5.

Mallikarjun, N., Venugopal, T.M., Suchitha, Y., Swathi, D., Kekuda, P.T.R., Vinayaka, K.S. (2011). Antibacterial activity of Chrysophyllum roxburghii G. Don Gen (Sapotaceae) leaves. Research and Reviews in Biomedicine and Biotechnology 2(1and2): 25-27.

Mallikarjuna, P.B., Rajanna, L.N., Seetharam, Y.N., Sharanabasappa, G.K. (2007). Phytochemical studies of Strychnos potatorum L.- A medicinal plant. E-Journal of Chemistry 4(4): 510-518.

Mohamed, A.A., Ali, S.I., El-Baz, F.K. (2013). Antioxidant and antibacterial activities of crude extracts and essential oils of Syzygium cumini Leaves. PLoS ONE 8(4): e60269.

Moreno, D.A., Ilic, N., Poulev, A., Brasaemle, D.L., Fried, S.K., Raskin, I. (2003). Inhibitory effects of grape seed extract on lipases. Nutrition 19:876-879.

Narotzki, B., Reznick, A.Z., Aizenbud, D., Levy, Y. (2012). Green tea: A promising natural product in oral health. Archives of Oral Biology 57: 429-435.
Sci. Technol. Arts Res. J., Jan-March 2014, 3(1): 14-20

Raghavendra, H.L., Kekuda, P.T.R., Valleesha, N.C., Sudharshan, S.J., Chinmaya, A. (2010). Screening for cytotoxic activity of methanol extract of Putranjiva roxburghii Wall (Euphorbiaceae) seeds. Phamacognosy Journal 2(10): 335-337.

Ramachandran, V.S. (2007). Wild edible plants of the Anamalais, Coimbatore district, western Ghats, Tamil Nadu. Indian Journal of Traditional Knowledge 6(1): 173176.

Ramaswamy, S.N., Rao, R.M., Govindappa, D.A. (2001). Flora of Shimoga district, Karnataka. Prasaranga University of Mysore, Mysore, pp 340.

Rekha, C., Poornima, G., Manasa, M., Abhipsa, V., Devi, P.J., Kumar, V.H.T., Kekuda, P.T.R. (2012). Ascorbic acid, total phenol content and antioxidant activity of fresh juices of four ripe and unripe Citrus fruits. Chemical Science Transactions 1(2): 303-310.

Sarangi, R.K., Kathiresan, K., Subramanian, A.N. (2002). Metal concentrations in five mangrove species of Bhitarkanika, Orissa, east coast of India. Indian Journal of Marine Sciences 31(3): 251-253.

Shi, Y., Burn, P. (2004). Lipid metabolic enzymes: emerging drug targets for the treatment of obesity. Nature Reviews Drug Discovery 3: 695-710.

Soetan, K.O., Olaiya, C.O., Oyewole. (2010). The importance of mineral elements for humans, domestic animals and plants: A review. African Journal of Food Science 4(5): 200-222.

Stoilova, I., Krastanov, A., Stoyanova, A., Denev, P., Gargova, S. (2007). Antioxidant activity of a ginger extract (Zingiber officinale). Food Chemistry 102: 764-770

Vinayaka, K.S., Kekuda, P.T.R., Kumar, R.K.A., Pavithra, G.M., Junaid, S., Rakesh, K.N., Dileep, N. (2013). Analysis of mineral elements of the lichen Usnea pictoides G. Awasthi by ICP-OES. International Journal of Chemical Sciences 11(3): 1589-1594.

Vivek, M.N., Manasa, M., Pallavi, S., Swamy, S.H.C., Kekuda, P.T.R. (2013). Antibacterial potential of Cashew apple (Anacardium occidentale L.) juice against clinical isolates of Staphylococcus aureus and Streptococcus mutans. Science, Technology and Arts Research Journal 2(3): 144-146.

Wojdylo, A., Oszmianski, J., Czemerys, R. (2007). Antioxidant activity and phenolic compounds in 32 selected herbs. Food Chemistry 105: 940-949.

Yamamoto, M., Shimura, S., Itoh, Y., Ohsaka, T., Egawa, M., Inoue, S. (2000). Anti-obesity effects of lipase inhibitor CT-II, an extract from edible herbs, Nomame Herba, on rats fed a high-fat diet. International Journal of Obesity and Related Metabolic Disorders 24(6): 758-764.

Yuan, Y.V., Bone, D.E., Carrington, M.F. (2005). Antioxidant activity of dulse (Palmaria palmata) extract evaluated in vitro. Food Chemistry 91: 485-494.

Yun, J.W. (2010). Possible anti-obesity therapeutics from nature - A review. Phytochemistry 71: 1625-1641.

Zhang, J., Kang, M., Kim, M., Kim, M., Song, J., Lee, Y., Kim, J. (2008). Pancreatic lipase inhibitory activity of taraxacum officinale in vitro and in vivo. Nutrition Research and Practice 2(4): 200-203. 